\title{
Nuclear physics for arms control
}

Two US and Soviet pressure groups have joined forces to produce a study of future goals in strategic arms control which is also an invaluable guide to the technical problems of verification.

THE usually combative demeanour of the Federation of American Scientists (FAS) exuded contentment at the modest ceremony last week at which it launched its latest study, with the Moscow-based Committee of Soviet Scientists (CSS), of the prospects for reducing stockpiles of nuclear weapons. True, only a few days earlier, Presidents George Bush and Mikhail Gorbachev had said they would sign a strategic arms control agreement before the year is out, which is consistent with what both pressure groups have been demanding, but the proposed treaty is likely to fall short of the 50 per cent reduction foreseen eight years ago, let alone of the 2,000 warhead limit for superpowers advocated by the new study. So why the contentment?

To be fair, Frank von Hippel of Princeton, co-editor with Roald Sagdeev of the Moscow Space Research Institute of the volume Reversing the Arms Race (Gordon \& Breach, New York; in press), made it plain that "START 1 should be quickly followed by START2", and it has been agreed that work should begin on the more ambitious treaty before the first is ratified (perhaps by the end of 1991). But nobody seems to think it feasible that the first treaty might be toughened before it is signed. Is it just possible that the arms control pressure groups have come to share with weapons manufacturers the sense of loss that an interesting problem has been snatched away?

That near-blasphemy is almost sustained by the fine print in this book, the first in a series under the title "Science and global security", whose appendices and footnotes deal absorbingly with the considerable technical problems arising in the course of verifying compliance with treaties that limit strategic arms. The fine print provides some intriguing information about the arrangements made for verifying compliance with the INF treaty restricting missiles of intermediate range. In passing, it also throws light on the problems of detecting forbidden objects and substances at civilian airports.

One has to marvel at the painstaking work that has gone into this fine print and also at the ingenuity. Who, for example, would have thought of sealing objects that must not be tampered with by roughly wrapping a bundle of optical fibres around them and recording the almost irreproducible pattern of light obtained by shining light down a few selected fibres?
The basic issue is that of detecting a nuclear warhead, or of telling whether a missile is thus equipped, by remote sensing alone. (The standard provisions of the INF treaty, being followed in START1, are that a missile owner's word may ordinarily be verified only instrumentally, but that each party to the treaty is allowed a quota of direct inspections 'on challenge' each year.)

Uranium and plutonium bombs present different problems. Although both materials emit neutrons (from spontaneous fission) and $\gamma$-rays (from fission, fission products and the products of radioactive decay), neutron detection is likely to be effective only for plutonium (which has the higher spontaneous fission rate). The study concludes that $\gamma$-detection is to be preferred for both, relying on the characteristic $1.001 \mathrm{MeV} \gamma$-ray from ${ }^{234} \mathrm{~Pa}$ (protoactinium-234) and the $0.662 \gamma$-ray from ${ }^{241} \mathrm{Am}$ (americium-241) in the decay chains of ${ }^{238} \mathrm{U}$ and ${ }^{241} \mathrm{Pu}$ respectively. Given time (to reduce background) and sufficiently sensitive detectors, these $\gamma$-rays may be detectable at ranges of several metres, even with portable detectors.

The snag is that neither of the characteristic $\gamma$-rays comes from the isotopes from which bombs are made $\left({ }^{235} \mathrm{U}\right.$ and ${ }^{24} \mathrm{Pu}$ respectively). Almost lovingly, there is an appendix describing how bomb-makers might plan to avoid the detection of their warheads by various devices - purifying weapons-grade $\mathrm{Pu}$ by separation of telltale isotopes (the high spontaneous fission rate of ${ }^{240} \mathrm{Pu}$, for example, is a potential giveaway.) Similarly, the remote detection of warheads made from ${ }^{235} U$ which are not equipped with a uranium tamper (tungsten is sometimes used instead) would be difficult.

So why not more active sensing devices? Radiography is a candidate, based on the relatively high stopping-power of nuclear explosives, but would probably require portable linear accelerators to be sensitive. (Some manufacturers' names are quoted.) By way of illustration, the report includes a $\gamma$-ray radiograph of a North American motor car which shows the engine to be in the front, where it belongs.

Neutron activation, which might have been thought the obvious candidate, requires surprisingly intense sources of 14 $\mathrm{MeV}$ neutrons to yield quick results by neutron detection (but there seems to be a future in the detection of fission-product $\gamma$-rays). This, of course, is where warhead detection and aircraft security may make common cause; civil aviation authorities hope that neutron activation machines can detect hydrogen-rich organic explosives, but the point has yet to be proved.

In this connection as in others, the new report suggests that, like nuclear physics itself, the refinement of techniques for warhead detection will hardly ever be complete. What FAS and CSS have between them done is to produce a vade mecum for the teams of nuclear physicists who will for decades hence be camped outside the gates of Soviet and US weapons plamts, counting warheauts âs they leave and enter, and a prospectus for research by those who stay at home.

Even the START1 treaty will require some means of verifying that information provided about sea-launched cruise missiles is correct. The essential difficulty is that the proposed treaty will limit the numbers of strategic warheads deployed by the Soviet Union and the United States, but that numbers of cruise missiles (some of which may carry conventional warheads) will not be limited. The problem does not arise with air-launched missiles, which will effectively be limited by the restrictions to be placed on the numbers of carriers (bomber aircraft) which are deployed.

A Soviet proposal that nuclear warheads might be detected from helicopters flying near ships equipped with nuclear warheads is floated in the new study, but the measurements reported (a decrease of neutron-count with distance) do not seem compelling. There seems nothing for it but on-board inspection - in which connection a US team reports the remote detection in the forward missile tube of a Soviet cruiser sailing in the Black Sea of a ${ }^{235} \mathrm{U}$ warhead at the tip of a cruise missile.

But plainly, on the evidence of this report, it is clear that sea-launched cruise missiles will be a headache for those who administer START1. Each signatory will have to provide the other with a list of how many nuclear warheads are carried on what ships, and the object of verification will be to ensure that the whole inventory remains what it is supposed to be. That will entail not merely the inspection of vessels in port and at sea, but also the monitoring of missiles as they are loaded and unloaded at predesignated ports. On the evidence of this excellent study, it is not surprising that these weapons have been a stumbling block in the negotiation of START1.

John Maddox 